\title{
Aportes de las teorías de la interpretación a los procesos de configuración textuales: ¿cuál es el papel del lector? ${ }^{1}$
}

\author{
Carlos Emilio Gende
}

\section{Presentación del problema}

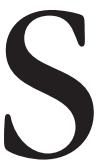

eñalo "aportes" con algo de imprudencia, dado que no sólo no hablaré de todas, sino ni siquiera lograré abarcar las más importantes teorías de la interpretación, pero a la vez lo hago con declarada prudencia epistémica, a los fines de que mediante el plural se le conceda a mi presentación no quedar constreñida a una versión más o menos clausurada de lo que podría esperarse respecto al papel del lector. En este sentido, como podrán apreciar, intentaré no venir a repetir conceptos de la hermenéutica ontológica ${ }^{2}$ o de la estética de la recepción, aunque sus aportes son invaluables, o al menos no lo haré sin ponerlos en contraste con algunas de las descripciones de la semiótica contemporánea, por señalar una escuela a confrontar.

Esto ya muestra de entrada que por interpretación se entienden procesos muy distintos y no siempre relacionados; no obstante ello, mi esfuerzo estará

${ }^{1}$ Agradezco las valiosas observaciones y preguntas que me hicieron llegar los evaluadores de esta propuesta, pues me han permitido detectar núcleos conceptuales que ameritaban explicitarse; aunque no pueda asegurar, por supuesto, haberlo conseguido.

${ }^{2}$ Con la expresión "hermenéutica ontológica" aludo a la caracterización habitual que se hace del lugar que ocupa la obra de Gadamer en relación con el legado de Heidegger. Coincido con Recas Bayón cuando señala que para ambos "[...] la comprensión no es primariamente un problema metodológico, sino, antes que nada, y en expresión de aquél, el modo de ser propio del ser-ahí (del Dasein), la especificidad constituyente de su finitud, el carácter previo, orginario y concomitante a todo otorgamiento de sentido y que abarca, por tanto, el conjunto de nuestra experiencia del mundo" (Javier Recas Bayón, Hacia una hermenéutica crítica. Madrid, Biblioteca Nueva, 2006, p. 141). Por su parte, con "hermenéutica crítica" caracterizo, sin por ello pretender oponerlos aunque sí distinguirlos, en especial la obra de Ricoeur. El "camino largo" adoptado por este último para emprender su tarea filosófica, la cual coincide, por cierto, en la preocupación ontológica, requiere, sin embargo, de un largo rodeo por las ciencias sociales, de cuyas enseñanzas se vale para un ejercicio interpretativo crítico con alcance epistémico. 
dirigido a tematizar lo que esta actividad pueda aportar para una mejor descripción de los procesos de configuración. Y entre éstos, para acotar mejor el objetivo de la exposición, los procesos de configuración literarios.

Ahora bien, ¿por qué haría falta revisar teorías de la interpretación que permitan dar cuenta de algo relativo a lo literario? Tal vez porque, como ocurre con todo concepto denso en nuestras disciplinas (la justicia para la filosofía del derecho, el Estado para la filosofía política, la ciencia para la epistemología, etcétera), lo literario se ofrece como lo incuestionable por obvio (¿quién no sabe a qué remite ese concepto?) y a la vez como lo más necesitado de explorar conceptualmente; pues en lo obvio subyace a menudo el malentendido que banaliza la riqueza de su experiencia. Como sostiene Terry Eagleton: "sin algún tipo de teoría -así sea irreflexivo o implícito- no sabríamos, en primer lugar, qué es una obra literaria ni cómo hemos de leerla. La hostilidad a lo teórico, por lo general, equivale a una oposición hacia las teorías de los demás y al olvido de las propias". 3

Así, el concepto de interpretación debería contribuir a delimitar, o al menos aproximar, un criterio que determine el campo de lo literario, en este caso desde el problema de la configuración y detectando con ello el papel del lector.

\section{El lugar de la teoría}

Si revisáramos su tan breve como esclarecedora Breve introducción a la teoría literaria, advertiríamos que ahí Jonathan Culler se interroga por la índole de lo literario, en el reconocimiento de que es indispensable contar con un concepto adecuado, pero con la sospecha de que quizá se trate de una empresa condenada al fracaso. Eso le lleva a destacar la importancia de la teoría -del abordaje teórico de un asunto- como modalidad intelectual altamente especulativa que, podríamos decir, sistematiza, organiza, exhibe las relaciones, pero que a la vez detecta las falsas ilusiones que llevan a los fracasos definitorios y totalizantes: el hecho, en definitiva, es que nunca hay suficiente teoría ni nunca agotamos la tarea interdisciplinar que las reúne. "La teoría intimida", sostiene Culler. ${ }^{4}$

Y para el caso, es ineludible que a la hora de dar cuenta de lo literario hagamos teorías, o al menos las aprendamos y abrevemos en ellas. Sin embargo, en relación con nuestro asunto podemos señalar que la posibilidad misma de una delimitación teórica ya es deudora de una interpretación que oficia de marco organizador del campo. Es como si dijéramos: no hay lo literario en

${ }^{3}$ Terry Eagleton, Una introducción a la teoría literaria. México, FCE, 2007, p. 10.

${ }^{4} C f$. Jonathan Culler, Breve introducción a la teoría literaria. Barcelona, Crítica, 2000, cap. 1. 
sí, pero tampoco cualquier empleo del lenguaje lo es, pues se constituye en función de alguna interpretación que lo demarca del resto de otras prácticas lingüísticas. El asunto problemático será que una vez reconocido esto deberemos aceptar la diversidad de interpretaciones, y ello nos conducirá a detectar interpretaciones rivales, interpretaciones en conflicto que, pareciera, sólo habría que asumir con resignada actitud, pero sin poder avanzar mucho más allá de detectarlas; como si la diversidad e incluso el conflicto fueran suficientes indicadores para abstenerse de un tratamiento laborioso del asunto. A esto se añade una circularidad tramposa, pues el único modo de resolución del conflicto vendría de la mano de un esclarecimiento teórico que lo superara, pero a la vez sostuvimos que lo teórico resulta de una interpretación que lo instaura, y así sucesivamente. En fin, no es mi propósito complicar estos asuntos o suponer que deban quedar en el terreno de las aporías, pero sí sugerir la relación interna de conceptos y prácticas.

Volvamos entonces. En primer lugar, ¿por qué no hay lo literario en sí?, porque a menos que banalicemos la especificidad de esta experiencia con el lenguaje y con el mundo, como ocurre, por ejemplo, cuando llega a sostenerse de un modo tan abarcador como poco interesante que toda práctica lingüística es literaria por principio - al no poder evitarse la retoricidad, o por el empleo inadvertido de metáforas, entre otros postulados-, es imprescindible elaborar categorías de análisis que recojan esa especificidad. Precisamente, la necesidad de teoría viene de la mano de advertir que no todo lenguaje es literario y que, sin embargo, no bastan nuestros recursos de sentido común para reconocerlo.

Hay indicios, por cierto, pero no son excluyentes ni exclusivos; por señalar algunos que sugiere el mismo Culler hacia el final de un apartado en el que declara la situación paradójica de la literatura como institución: ${ }^{5}$ la suspensión de una inteligibilidad inmediata, la reflexión sobre los medios de expresión, la atención a cómo se producen el significado y el placer. A continuación haré un breve comentario respecto de estos rasgos, para lo cual debo abandonar la perspectiva del autor, pues creo encontrar entre ellos una relación interna que los reenvía de uno a otro, proceso que nos permitirá aproximarnos mejor a nuestro objetivo.

Si algo nos ubica de otro modo ante un fragmento lingüístico es, en una primera lectura, su opacidad. Un texto determinado se nos resiste, pero nota-

${ }^{5} C f$. "La paradoja de la literatura", en ibid., cap. 2. Al respecto, cabe mencionar a Derrida, quien sostendrá en una entrevista que la paradoja de la literatura como institución consiste en que se trata de una institución de legitimación mediante convenciones y reglas; sin embargo, mediante la ficción habilita a un decir sin límites, desplazando las reglas y permitiendo poner en duda las bases mismas que la constituirían como institución (véase Derek Attridge, Acts of Literature. Londres, Routledge, 1992, apud Fernando Romo Feito, Hermenéutica, interpretación, literatura. Barcelona, Ánthropos, 2007). 
mos que es debido a algo anterior al asunto, o contenido al que pretendemos acceder, y al modo en que se dispone. No se trata de la dificultad para entender qué se dice, o no sólo eso, sino algo anterior, cómo se dice de ese modo. Se presupone un significado, pero no se accede de modo directo a él. ¿Porque dice algo más que lo manifiesto en una primera lectura? ¿Y ese plus, es otra cosa? ¿Y esa otra cosa, es distinta o incluso opuesta a la manifiesta? Aparece así una serie de asignaciones de significado in crescendo, que provoca inferencias sucesivas hasta el punto de abarcar incluso las opuestas a la primera impresión de superficie; y todo ello a partir de una resistencia dada por el modo en que se dice. Sin embargo, más allá de estas sospechas sobre segundos significados, la cuestión es que el fragmento dice. Entonces, de esa doble situación: la asignación presunta de contenido y la dificultad para dar cuenta de él de modo transparente, podría surgir una primera experiencia de lo literario. ¿Por qué?, porque con ello descubrimos la necesidad de explorar los medios y recursos que permitieron que se haya dicho de ese modo, tan específico ${ }^{6}$ y extraño a la vez (segundo rasgo). Detecto la no transparencia, pero al mismo tiempo rechazo la asignación de error, y con ello supero el malentendido, acto interpretativo por excelencia, dicho sea de paso. ${ }^{7}$ Pero entonces va de suyo la necesidad de explorar el recurso, de revisarlo como recurso expresivo tal o cual.

${ }^{6}$ Respecto a la experiencia de especificidad, remito a la descripción de Gadamer sobre la tarea del poeta y su búsqueda incesante de la palabra justa. Véase, por ejemplo, Hans-George Gadamer, "Los límites del lenguaje", en Arte y verdad de la palabra. Barcelona, Paidós, 1998. Extraigo algunas consecuencias de esta descripción gadameriana en relación con los límites del lenguaje como expresión de nuestra finitud (véase Carlos E. Gende, "El giro lingüístico como giro ontológico en la hermenéutica gadameriana", en Mariflor Aguilar Rivero y María Antonia González Valerio, Gadamer y las humanidades. I. Ontología, lenguaje y estética. México, UNAM, Facultad de Filosofía y Letras, 2007).

${ }^{7}$ Por cierto, Gadamer objetaría que la tarea hermenéutica consista en la superación del malentendido, propósito que le atribuye a Schleiermacher. Sin embargo, entiendo la objeción como crítica a un modelo propio de la modernidad que, según el mismo Gadamer, habría transferido al trato humano rasgos provenientes del trato con la naturaleza: el extrañamiento y el afán de dominio, entre otros. En ese sentido, por cierto, la hermenéutica que sostuviera su tarea como superación del malentendido heredaría la creencia errónea, según este autor, de que el punto de partida para la interpretación consiste en suponer que, en principio, no comprendo al otro y debo esforzarme metodológicamente para superar ese escollo. Sin embargo, lo que a partir del segundo rasgo -que tomo de Culler- lo que pretendo mostrar es que habría una experiencia típica en la lectura que consiste en asignar sentido y, a la vez, no poder dar cuenta de él de modo transparente. Sé -sospecho al menos- que no puedo atribuir error o falta de claridad expositiva al fragmento leído, como recurso para justificar mi incomprensión, y por ello insisto con la atribución de sentido, pero tampoco logro asirlo en una primera lectura. Y eso, propongo, es una experiencia interpretativa en relación con el malentendido y de cómo debo trabajar para superarlo a partir de explorar los recursos que configuran el texto. 
A hora bien, el trabajo exploratorio sobre el recurso o disposición no sólo es a expensas de volverlo inteligible como tal, con la finalidad de dominarlo, de volverlo procedimiento manipulable, sino también porque ha resultado disfrutable y queremos entender cómo ocurrió ello (tercer rasgo). Umberto Eco señala como justificación a sus textos teóricos lo siguiente: "había que optar entre hablar del placer que proporciona el texto o de las razones en virtud de las cuales el texto puede proporcionar placer. Hemos optado por esta última alternativa", ${ }^{8}$ es decir, ante todo elige una actitud prescriptiva en desmedro de una actitud descriptiva, porque las razones que elabora tienen como objetivo último establecer el sistema de reglas fundamentales para detener la semiosis infinita. Pero también se trata, en el caso de lo literario, de hablar del placer, de teorizar sobre ello y, en el mejor de los casos, lograr una valoración ${ }^{9}$ adecuada.

Entonces, estamos ante una experiencia lingüística en la que no sólo se habla de algo, sino que importa saber de qué modo, venciendo las resistencias del recurso y, a la vez, por la vía de examinar las condiciones del placer que nos produce ese modo y no otro de presentar el asunto.

Con esto tenemos al menos tres cuestiones de las que debemos hacernos cargo con nuestras teorías: cómo explorar la dificultad constitutiva que se resiste a una lectura lineal; cómo reconocer en ello la emergencia de recursos específicos que vuelven a ese dispositivo, curiosamente, condición para la inteligibilidad, y, finalmente, cómo todo eso surge en un momento de lectura que disfruta de lo que lingüísticamente allí ocurre.

Reconozco que puede tratarse de asuntos difícilmente conciliables, pues en una inspección rápida bien cabe objetar que trabajar para vencer la dificultad y/o extrañeza no resulta algo placentero de suyo (a menos que se trate de un masoquista declarado). Sin embargo, no estamos sosteniendo la subordinación de una experiencia a la otra, sino, al contrario, lo que quisiera sugerir es que se trata de dos modos de tratar interpretativamente con un texto que habilitan, ambos - cada uno a su modo, pero confluyendo en un mismo resultado-, para resolver la lectura bajo la condición de que lo ahí dispuesto es una configuración literaria.

No es que necesariamente me produzca placer toparme con resistencias, se trata simplemente de que hay algo ahí que me produce placer: su musicalidad, su organización transfrástica, su estilo tal vez; la forma, para sintetizar en una expresión conocida. Y por otra parte, no me sostengo en una lectura literal, porque tengo la sospecha de que de ese modo no lograría dar con el sentido,

${ }^{8}$ Umberto Eco, Lector in fábula. Barcelona, Lumen, 1993, p. 22.

${ }^{9}$ Aludo ex profeso a valoración, pues no se trata de una actividad descriptiva, o al menos es una descripción también valorativa. 
por lo cual tendré que esforzarme para superar la impresión de superficie. Si se me permite la metáfora, es como si viéramos trabajar dos fuerzas contrapuestas: de atracción y de repulsión, y de ambas resulta la configuración como disposición específica del texto.

\section{Figuras de lector y su relación con el texto}

Acabo de escribir "texto" cuando al comienzo aludí a "fragmento lingüístico". El lapsus debe ser aprovechado, pues precisamente si algo debe quedarnos en claro, para todo lo que queremos comentar aquí, es que la única unidad de análisis que cabe considerar es la de texto; es decir, no es la palabra ni el enunciado. Tampoco lo es la explicación del primero por algunos de los dos últimos. Y esto con los fines de no dar lugar a pseudo problemas que surgen sólo de una inspección artificial de lo que nos ocupa, como ha ocurrido en algunas discusiones de la escuela analítica cuando debatieron sin fin alrededor de expresiones como "el rey de Francia es calvo", y ejemplos por el estilo, olvidando que si se trata de enunciados en una práctica comunicativa oral, sólo cobran sentido en un diálogo y si se trata de una práctica escrita, sería improcedente esperar algo de una frase aislada de su relación con la totalidad del texto.

El texto es una unidad de organización completa que trasciende la concatenación de frases, es ése y no cualesquiera; por lo cual se trata de un singular que no puede ser subsumido en una generalidad abstracta. Su configuración literaria responde también a rasgos universalizables: tipologías, cánones, géneros; sin embargo, no es reducible a ellos. Por eso merece ser interpretado, es decir, merece ser leído en tanto singularidad a partir de la cual inferimos conjeturalmente su sentido.

¿Por qué estoy ligando ahora interpretación a un proceso de inferencia conjetural? ¿Y qué relación guarda ello con la lectura? Decíamos antes que ante el texto literario presuponemos sentido, asignándoselo como modo de vencer su resistencia. Ahora bien, ¿qué se busca en ese acto?, ¿qué puede querer resolverse en ese acto de presuposición que asigna sentido? Veamos algunas posibilidades e intentemos detectar en figuras posibles de lector si acaso se trata de actos interpretativos: $a$ ) un caso sería el de aquel que se propone remontar el trabajo de composición buscando las claves ocultas en el texto, sedimentadas en él como dispositivos retóricos o poéticos y disponibles para decodificarlas como estructuras autocontenidas, sin necesidad de remisión a lo otro del texto; $b$ ) otro caso sería el de aquel que pretende conocer al autor mejor de lo que él pudo, proponiendo entonces versiones extra textuales, pero en clave de tal o cual sistema de ideas preestablecido; se trata del modelo que cree hallar algo que está por detrás del texto, en un momento anterior, como 
si se tratase de un contenido "verdadero" bajo una modalidad desconocida para el propio autor y que incluso lo utiliza a él como vehículo mediador del sentido ya dado y acabado: el autor y su obra como emergente de una voluntad de poder, una conciencia de clase o una pulsión inconsciente; ejerciendo el lector sobre todo ello la sospecha; ${ }^{10} c$ ) habría también una caracterización del lector como aquel que ambiciona capturar, para coincidir con sus destinatarios originarios, el momento inaugural de producción del texto, como si esa filiación histórica lo habilitase a acceder a una formación de sentido más auténtica y plena. También aquí se trata de asegurar el sentido como aquello pre-dado, pero en este caso por la vía de la remisión al momento sociohistórico antes que por el exclusivo anclaje en la biografía del autor como transporte de un sentido ignorado por él, y, finalmente, $d$ ) abandonadas estas presuposiciones por inconducentes, y ya en una explícita posición que se declara escéptica de poder lidiar con un texto en términos de búsqueda de sentido, aunque a la vez fascinada por las posibilidades que se insinúan en su trato - posibilidades que resultan, no obstante, de un recorrido que sólo se mide con sus perspectivas más personales e incuestionadas-aparece la figura del lector libérrimo que se autosatisface haciendo del texto una fuente inagotable de justificaciones de lo que ya sabía o quería encontrar, de lo que siempre "supo" y no está dispuesto a modificar. Es el lector que se espejea ante el texto, o mejor dicho, que hace del texto un reflejo de él.

A riesgo de simplificar mi exposición, sostengo que es posible reunir estas descripciones como modalidades todas de un lector que decodifica, pero no que interpreta. ¿Por qué?, porque se presupone una relación con la verdad que de algún modo ya está asegurada -codificada- y la lectura sólo trabaja en pos de detectarla y asegurarse así el sentido. Sentido, a su vez, que ya está dado: preexiste en una configuración cerrada en su autonomía como forma, si se trata de la primera versión, y que está cerrada en un mundo de la vida fijo y pleno, completo en su verdad, al que remite el texto como su duplicación o reflejo, en las tres siguientes. ${ }^{11}$ Con esto la lectura se convierte en una excusa para otra cosa: asegurarse que estamos en la verdad. En la primera, el texto como artefacto semiótico autocontenido y en las siguientes, como vehículo

${ }^{10}$ En este punto aludo a la descripción que realiza Paul Ricoeur de los tres tipos de presupuestos que caracterizan lo que ha denominado "filosofía de la sospecha" (cf., por ejemplo, Paul Ricoeur, La metáfora viva. Madrid, Trotta, 2001, p. 399).

${ }^{11}$ Aun en la cuarta figura ocurriría lo que describo, pues pretender que la lectura consista sólo en la expresión de mi impresión personal, de lo que a mí me parece porque a mí se me aparece un sentido tal o cual, es una defensa implícita del sentido como aquello pre-dado y concluido, en este caso del modo más pedestre: por remisión, si es que fuera posible sostenerlo, a un mundo personal que predispone y clausura las lecturas. 
de un querer decir que se supone pleno y pretérito. El papel del lector aquí se realiza en función de detectar la clave de lectura que lo legitima en su acto, por lo cual el texto es un caso subsumible en el código que lo explica; o bien, en el último caso, prescindiendo ya de ese trabajo, sólo se lee para autoafirmarse en los datos que le provee su propia perspectiva de lector.

Como puede advertirse, presento dos posibles clasificaciones que distribuyen los cuatro casos de manera distinta, según el criterio implícito adoptado, pero que confluyen en una misma descripción. En la inmediata anterior, establezco una distinción usual entre forma y contenido. Así, se presupone el código como forma estructurada inmanente al texto -en la primera figura-, o se lo presupone como contenido anterior que el texto vehiculiza -en las tres figuras restantes. En esta segunda clasificación destaco posibles modos de describir el papel del lector: como aquel que pretende sólo decodificar (por la forma y/o por el contenido, en las tres primeras) o como aquel que se satisface en su perspectiva (en la última). Sin embargo, como señalo en la primera clasificación, aun este último rol no deja de ser una variante - por la negativa- de la lectura entendida como decodificación; en este caso por reducción al punto de vista del lector. De ahí que, como sostendré en seguida, ninguno de estos casos consiste en una actividad interpretativa. Tanto el trato con textos que supone la remisión a lo hipercodificado, como el que remite a lo hipocodificado, son variantes, ambos -opuestos, por supuesto-, de un modo de lectura que no interpreta. ${ }^{12}$

En un esquema opositivo muy tradicional diría que así descritas las versiones, la lectura o bien sólo procura explicar o bien sólo comprender; con otro vocabulario diría que trabaja en pos de una objetividad univocista (en las tres primeras) o descansa - nunca mejor dicho- en una subjetividad equivocista (en la última). ${ }^{13}$ Pero, insisto, no interpreta. Y no lo hace porque la descripción, al oponer de modo tan radical estas pretensiones, exacerba la sedimentación a

${ }^{12}$ Para una descripción más circunscripta a la posición de Ricoeur, remito a C. E. Gende, Lenguaje e interpretación en Paul Ricoeur. Buenos Aires, Prometeo, 2005, especialmente los caps. 5 y 6 , donde desarrollo algunas de las consecuencias que extrae el autor de las teorías de la recepción.

${ }^{13}$ Para una presentación de enormes consecuencias heurísticas de esta puja entre univocistas y equivocistas, y de cómo superarlas, remito a la vasta obra de Mauricio Beuchot: la hermenéutica analógica (véase, por ejemplo, Mauricio Beuchot, Tratado de hermenéutica analógica. Hacia un nuevo modelo de interpretación. 3a. ed. México, UNAM, Facultad de Filosofía y Letras/Itaca, 2005). Cabe señalar que esta clasificación viene a complementar las anteriores, pues permite redistribuir las cuatro figuras de lector en una oposición muy bien desarrollada por la hermenéutica analógica: entre univocismo y equivocismo. Como sostiene Beuchot, tanto si presupongo un solo sentido que debo detectar como si presupongo la imposibilidad de asir alguno que sea suficiente, aunque provisorio, no interpreto. 
que responde un texto, como lo dado e inalterado, pero extrínseco al trabajo del intérprete, o la presunta innovación, vacía, que entonces no se compromete con el asunto del texto. Es que leer un texto, valga señalar la obviedad, exige entrar en tratos con él y esto supone, como procesos de interacción efectivos, tanto su comprensión como su explicación; pero con los fines de que resulte una nueva figura en el lector, la apropiación.

Veamos con algún detalle estos procesos: comprender un relato, como primer momento inicial, ${ }^{14}$ consiste en lanzar conjeturas sobre su inteligibilidad, desplegando con ello la competencia para seguir una historia. ${ }^{15}$ Conjeturas que apuntan, como señala Paul Ricoeur, a "prender conjuntamente las peripecias, el nudo, el desenlace, de modo que se integren finalidad, causalidad y contingencia en totalidades significativas", es decir, apuntan a reponer la configuración del texto como dispositivo organizado en una totalidad singular con recursos muy específicos. Ahora bien, comprender es también disponerse a disfrutarlo, entregarse expectante al placer de las sugerencias de sentido que abren un espacio disruptivo inicial, a partir del cual se realizarán las segundas lecturas, temáticas o críticas. ${ }^{16}$ Por su parte, explicarlo consistirá en responder a la demanda de justificación de esa expectativa en tensión con la otredad del texto, como artefacto semiótico que genera y prescribe sus recorridos posibles. Esa respuesta inicial, y las sucesivas, en una cadena que en principio no se detiene, revelan una tensión entre la persistencia por hacer prevalecer el punto de vista propio y las resistencias que le oponga la otredad del texto. En ese proceso continuo y autocorrectivo va emergiendo otro plano de la configuración del texto, pues logra salirse de sí e ingresa al mundo, se realiza el acontecimiento de sentido en algo que le es externo, pero a la vez él lo dispone, mejor dicho, lo predispone. Ya no es sólo tratar con la inmanencia de su estructura ni tampoco con la trascendencia, entendida como supuesta anterioridad que le aseguraría su sentido; supuesta, digo, porque se trata de

14 "Primer momento" sólo a los fines de una reconstrucción analítica, pues no habría modo de separarlo de hecho del proceso explicativo que acompaña a la comprensión. Por otra parte, esta caracterización de la comprensión como apuesta conjetural respecto a la inteligibilidad sería extensible a otros tipos de textos, dado que el acto inicial de atribución de sentido por parte del lector consistiría siempre al menos en adjudicarle una pertenencia a un género o tipo determinado.

15 "La intelección narrativa es nuestra capacidad aprendida con la cultura de prenderconjuntamente las peripecias, el nudo, el desenlace, de modo que se integren finalidad, causalidad y contingencia en totalidades significativas" (P. Ricoeur, "Hermenéutica y semiótica", en G. Aranzueque, ed., Horizontes del relato. Lecturas y conversaciones con Paul Ricoeur. Madrid, Cuaderno Gris, 1997, p. 99).

${ }^{16}$ Al respecto, Ricoeur abreva en la "Estética de la recepción" de Jauss, quien rehabilita el papel que cumple el goce y su relación primitiva con el conocimiento ( $\mathrm{P}$. Ricoeur, Temps et récit. III. Le temps raconté. París, Seuil, 1985, p. 320). 
una anterioridad inhallable de otro modo que mediante reenvíos de texto a texto, pero sin anclaje en una referencia a la mano.

Ahora bien, si el texto logra salirse de sí, e insisto, y no para reenviarse a un mundo pretérito, lo es a instancias del acto del lector; lector que, como intérprete, realiza en sí mismo, pero ante el texto la síntesis provisoria y sujeta a cambios de comprensión y explicación, obteniendo como resultado la apropiación transformadora de sí. Dicho de otro modo, el lector interpreta un texto en tanto y en cuanto se descubre transformado respecto a sus presuposiciones iniciales, tanto las que tiene en relación con lo que el texto parece decir como en relación con sus perspectivas previas a la lectura. En ese sentido, las versiones de lector que describimos antes son todos momentos posibles y en ocasiones necesarios para la apropiación, pues muestran, como señalamos, la preponderancia o bien de la sedimentación, que vuelve previsible el sentido presunto, según la clave tal o cual que el lector logra decodificar, o bien de la innovación, como acto que se pretende, de modo engañoso, por fuera de todo esquema de reglas y normas. Sin embargo, la interpretación, como creatividad regulada, trabaja a partir de la tensión de esas dos modalidades y estabiliza transitoriamente un resultado.

\section{El lector transformado}

A los fines de aproximarnos a una noción de transformación como resultado del acto interpretativo del lector, les propongo tomar como caso de aplicación la respuesta que da el poeta chileno Gonzalo Rojas ante la pregunta sobre su identidad, en una entrevista que le realizó Andrés Hax para la revista $\tilde{N}$ : "¿si lee su primer libro La miseria del hombre ve al mismo poeta que es hoy?”, pregunta Hax. El escritor contesta:

[...] sin jugar con ningún vocablo, ni palabras, ni nada de eso. Soy el mismo. Y en mí se ha operado algo así como la metamorfosis de lo mismo. Lo que te quiero decir es que soy el mismo. Creo ser. Es tan difícil decir soy. Siempre será difícil decir soy. Pero creo ser el mismo lector, intra-lector de siempre desde niño. Y el mismo que está apostando a decir mundo, nada más. ${ }^{17}$

"Y nada menos", completaríamos. La pregunta gira en torno a la capacidad de reconocerse como el mismo, suponiendo la diferencia entre la obra

${ }^{17}$ Gonzalo Rojas, "Una clase de poesía al estilo Rojas", entrevista de Andrés Hax en Ñ. Revista de Cultura, núm. 156. Buenos Aires, Clarín, 2006, p. 6. 
temprana, de la que debería hacerse cargo el autor, y su producción reciente. Diferencia, en principio, sólo afectada por el tiempo, por el transcurrir del tiempo que todo lo modifica; no sólo el tipo de producción intelectual, sino la autoaprehensión, la autoevaluación que puede hacerse sobre ella, hasta un punto tal que podría ocurrir que la respuesta fuese negativa: "no, ya no me reconozco en aquella obra, soy otro, he cambiado; no soy el mismo... y valga como prueba esa, mi obra temprana". O, en sentido opuesto: "sí, soy el mismo aun en las diferencias apreciables por el contenido, el estilo, la ambición ahora atenuada".

Gonzalo Rojas no adopta ninguna de estas respuestas y descarta la certeza imposible de ambas al contestar: "soy el mismo, creo ser". Cabe atender al matiz del "creo", que transmuta certeza en testimonio. Pero cabe también atender al reconocimiento de la dificultad que orienta la autodescripción: "soy", en tanto me reconozco intra-lector y decidor de mundo.

¿Por qué la pregunta al poeta sobre su mismidad? He ahí la obra, la exteriorización de su subjetividad que da cuenta con el designador rígido de su nombre de la autoría sostenida en el tiempo. Seguramente porque las diferencias son notables; así como él ha cambiado también su obra. Se espera entonces una autoevaluación que pueda superarlas subsumiéndolas en algún principio ordenador de su cronología, que le dé sentido al cambio según un modo de permanencia que no se sostiene en la mismidad de lo inalterable, de lo idéntico, sino, por el contrario, que como ipseidad se sostenga en el cambio, no a pesar del cambio.

Soy el mismo, dice el poeta: ¿el que no cambia?; no, soy la metamorfosis de lo mismo, es decir, soy el mismo en tanto cambio, porque cambio y me reconozco en él. Entonces, ser uno mismo es ser el que cambia, ¿̇acaso es esta la respuesta? Si así fuera, optaríamos por la banalidad de una aserción insuficiente, una que no da cuenta del asunto, como tampoco lo haría una opción por la permanencia. "Creo ser", sostenemos, es como transición en la frase algo distinto que un debilitamiento de la certeza; más bien orienta la respuesta hacia la necesidad del testimonio que se apoya en la propia experiencia, en lo que de ella resulta. Su experiencia, la de este poeta en particular, es la de decidor de mundo e intralector de sí; de allí que pueda ser privilegiado su testimonio para reconocer lo difícil que es decir "soy el mismo". Paul Ricoeur podría comentar al respecto: "decir sí no es decir yo. El yo se pone, o es depuesto. El sí está implicado de modo reflexivo en operaciones cuyo análisis precede al retorno a sí mismo".$^{18}$ En este caso, nos interesa advertir que las operaciones reconocidas son las de lector -intralector- $\mathrm{y}$ decidor de mundo.

\footnotetext{
${ }^{18}$ P. Ricoeur, Sí mismo como otro. México, Siglo XXI, 1996, p. XXXI.
} 
No obstante, el tipo de cambio descripto por Gonzalo Rojas es vivido por él como metamorfosis, no como simple transcurrir. Al respecto, si asociamos la noción de interpretación de sí con la de procesos de semiosis -como lo sugiere Josef Simon- podemos reconocer lo siguiente como caracterización interesante de la transformación:

[...] ocurren signos, esto es, los signos llegan a ser entendidos o quedan sin entender hasta que alguien llega a transformarlos en signos inteligibles. Esta transformación — que lo es también del sujeto que entiende cuando rebasa su propia representación de sí mismo como identidad-es el acontecer de los signos. El sujeto se ve arrastrado por el signo, más allá de su identidad, a otra distinta, y desde esta nueva vuelve a intentar entenderse como identidad en conjunto. ${ }^{19}$

La metamorfosis es mutua: se realiza la inteligibilidad de la semiosis, por ejemplo de un texto, como proceso de transformación de unos signos en otros mediante interpretaciones sucesivas que hace un lector y cuyo resultado es siempre provisional; a la vez que se realiza la inteligibilidad de sí mediante la apropiación de esos resultados como auto transformación.

\section{El aporte de la interpretación}

Con el postulado de esta doble transformación interpretativa que se realiza en continuos reenvíos de una en otra, del lector al texto, del texto al lector y así sucesivamente, estamos sugiriendo hacia el final de nuestra exposición un posible punto de encuentro entre dos enfoques que suelen proponerse como excluyentes para la teoría literaria: poética y hermenéutica; pues pareciera que se teoriza sobre los mecanismos y procesos que explican el diseño de un texto y de cuya posesión depende la competencia para ser un buen lector, o bien se teoriza sobre las condiciones que habilitan a que el significado de un texto dé cuenta del mundo extralingüístico. ${ }^{20}$

Cabe sospechar que ese tipo de oposición es heredero de una tendencia muy instalada en una cultura como la nuestra que, acostumbrada a separar los saberes en compartimientos estancos, le adjudica a la literatura un lugar de importancia, incluso privilegiada, siempre y cuando quede en claro que

${ }^{19}$ Josef Simon, Filosofía del signo. Madrid, Gredos, 1998, p. 154.

20 "La poética parte de efectos o significados comprobados y pregunta cómo se logran [...] La hermenéutica, por su lado, parte de los textos y se pregunta qué significan, procurando descubrir interpretaciones nuevas y mejores" (J. Culler, op. cit., p. 78). 
su alcance queda restringido a ser vía de expresión de las emociones. Esto obedece a una distinción incuestionable, pues se la toma por obvia, entre lenguaje informativo y lenguaje expresivo, según la cual se procede entonces a ubicar las pretensiones cognitivas en el primero y las emotivas en el segundo. Lo que hemos estado defendiendo en nuestra exposición intenta contribuir a desmontar esa distinción, no para invertirla sino para sugerir -señalamos al comienzo- la relación interna entre conceptos y prácticas. Y a estos fines, la actividad interpretativa, enfocada en la tarea del lector frente a un texto, y en especial el literario, contribuye a reconocer y aprovechar la relación mencionada.

Si abusamos un poco más de los esquemas opositivos podremos extraer otras consecuencias que nos orienten en el objetivo: la actividad puramente cognitiva decodifica el sentido pre-dado, universalizable y objetivable; la actividad puramente emotiva expresa la vía subjetiva del receptor, singular y personal. Otra vez la disputa entre univocismo y equivocismo, ahora orientada según una oposición cognitivo/emotivo que, insisto, viene operando como trasfondo no revisado del funcionamiento lingüístico.

Ahora bien, trasladado este esquema al trato con el texto literario, lo que de cognitivo pueda hallarse en él queda restringido a detectar su funcionamiento, a describir la maquinaria que lo estructura, inmanente y sin mundo del que hable. De ahí que un lector insatisfecho ante semejante propuesta opte por emplear al texto como excusa para su querer decir, para dar rienda suelta a la expresión del ocasional modo en que se le aparezcan las cosas, aunque concediendo de modo implícito que su tarea no es cognitiva. Pero así establecidos los posibles tratos no hay mundo desplegado por el texto, pues se lo ignora: o bien porque no se pretende que el texto hable más que de sí mismo -de su funcionamiento- o porque sólo prevalece la visión propia del mundo, como efusión personal. ¿Cómo se propone usualmente salir de esta oposición, que en definitiva opone forma a contenido - la forma del texto, inmanente, o el contenido, como posibilidad del receptor que mediante aquella se expresa? Curiosamente, también por fuera del texto; ahora la lectura no sólo trabaja con el código de la estructura, sino también con el del contenido, que ya no es el de la experiencia personal del lector, sino el que el texto vehiculizaría: la ideología que lo sustenta, la cosmovisión a que responde, la localización sociohistórica contingente en que surgió, etcétera. Por eso afirmamos que en ninguno de estos casos la lectura es interpretativa, sino decodificadora. Trabaja ante un texto, sí, pero como pretexto; no como texto, con él. Es que aquí el texto es un vehículo, que habla de sí mismo como forma o de otra cosa como contenido, pero no como texto. Y ambos, forma inmanente y contenido trascendente, son los posibles cognados, son lo dado a conocer; pero porque se los supone previos, ya dados, y el texto simplemente los vehiculiza. Si se me 
permite algo de exceso en la clasificación de escuelas, diría: estructuralismo, para lo primero, psicología y/o sociología de la lectura, para lo segundo. Con ellas, la literatura cumple una función pedagógica, "enseña", pero otra cosa: sistema de la lengua, sistema de ideas, sistema de reglas, etcétera, no como texto literario, en su especificidad. ${ }^{21}$ Sugiero a la vez que este prejuicio es deudor de otro, más constitutivo, acerca de nuestra descripción lingüística, que consistió en subsumir al lenguaje en signo y a partir de lo cual resulta la disposición binaria: significante/significado. Así, si la palabra vehiculiza ideas y el enunciado estados del mundo, el texto vehiculiza sistemas ya configurados. ${ }^{22}$

De ahí que si retomamos nuestra descripción que recoge la tensión entre resistencia por opacidad y atracción por placer, podríamos tal vez advertir que la experiencia literaria es privilegiada para disponernos a un modo de lectura que asuma el desafío de la doble transformación aludida y, por ende, que muestre el resultado efectivo de la lectura como despliegue de las nuevas posibilidades que se abren ante el intérprete como horizonte de mundo.

En efecto, el texto literario predispone desde su propia configuración -dadas las características especiales que exhibe su diseño-a hacerse cargo de la resistencia que nos ofrece a los lectores que desearíamos hacer prevalecer nuestras ilusorias pretensiones, como portadores de sentido. Resistencia, en principio -señalamos-, por el modo en que se dice, modo opaco, indirecto, figurado; pero atractivo a la vez, invitación al disfrute. ¿Es la vía del placer, entonces, la que induce la apuesta al sentido? Al menos contribuye a no atribuir error o falsedad al texto que se resiste, y así predispone a interpretarlo. Pero también orienta la lectura a detenerse en ese modo, no reemplazable mediante paráfrasis o traducción a un lenguaje supuestamente más transparente. Si el texto no vehiculiza un sentido tal o cual, sino lo constituye junto al acto del lector intérprete, y con ello abre un mundo, es debido a que lo que dice sólo se sostiene en su especial disposición lingüística.

Ahora bien, ¿qué resulta de vencer la resistencia?, tarea nunca agotable por otra parte. La apropiación, entendida como transformación del lector por y en el texto. La interpretación, entonces, es un proceso que se da por el texto, singular y específico en su disposición no idéntica a otros textos, pero en el lector. ¿De qué modo, por su comprensión o por las explicaciones que sea capaz de dar? Por ambas. Ricoeur lo sintetiza de modo elocuente: "explicar

${ }^{21}$ Es como si las tareas quedaran delimitadas de este modo: el autor de literatura se expresó vía su obra. Luego, el lector lego la disfruta a su modo, expresándose vía la obra, pero sin otra preocupación que esa; y el lector competente la explica, como estructura o como vehículo de ideas.

${ }^{22}$ Esto permitiría entender a qué obedece la transpolación ingenua de propiedades de la palabra al enunciado y de este al texto, como si se tratase de estructuras subsumibles unas en otras, a modo de "muñecas rusas". 
para comprender mejor". ${ }^{23}$ De este modo, lo que resulta es una interpretación que vence las resistencias no sólo de la específica configuración del texto -por el modo en que dice-, sino de las propias resistencias como lector, que cree entender las cosas de un modo u otro, modo encorsetado que debe ponerse entre paréntesis para aceptar el desafío del texto. La resistencia a vencer, entonces, es la de una visión del mundo clausurada, aquella que supone el trato con el sentido como si fuera el trato con lo dado. Frente a eso, la lectura exige la remoción de los presupuestos de esa visión de mundo como condición para un interpretar genuino, pero con ello, claro, la lectura exige también la remoción de los nuestros.

\section{A modo de balance}

En nuestro recorrido, hemos intentado ofrecer una caracterización de la interpretación como actividad especialmente adecuada para recoger los resultados instructivos del trato con un tipo específico de configuración lingüística: la realizada en los textos literarios. Se trata de un concepto de interpretación que permite describir el acto de lectura como estabilización transitoria de procesos, en constante reenvío, de comprensión y explicación. Lo que se estabiliza redunda en una transformación del punto de vista inicial del lector, a la vez la condición transitoria proviene de la disponibilidad que ese anclaje del lector proyecta en nuevas posibilidades de sentido.

Por su parte, si hacia el final pudimos señalar que el propósito último de la interpretación consiste en trabajar para remover la presuposición ingenua de nuestro trato con el sentido como si fuese lo dado, es porque se trata de una actividad que muestra su efectividad, diría incluso su productividad, en tanto y en cuanto renuncia tanto a la pretensión de certeza como a la disolución del sentido en la mera exhibición del punto de vista. Este doble rechazo exige del lector volverse intérprete, de sí ante el texto y del texto ante sí, es decir, exige asumir lo que Wolfgang Iser propone como un resultado de trasfondo: "la interpretación indica lo que tal vez signifique llevar una vida consciente impregnada de la conciencia de la incomprensibilidad de donde surge". ${ }^{24}$ Resultado desconcertante, tal vez, al momento de proponer una conclusión - provisoria- a mi escrito. Sin embargo, si la interpretación de textos queda bien caracterizada como proceso inferencial que trata con una configura-

23 "[...] fórmula que, de algún modo, se convirtió en la divisa de la hermenéutica, tal como yo la concebía y practicaba" (P. Ricoeur, Autobiografía intelectual. Buenos Aires, Nueva Visión, 1997, p. 53).

${ }^{24}$ Wolfgang Iser, Rutas de la interpretación. México, FCE, 2005, p. 307. 
ción singular y única, inferencia que explica más para comprender mejor y comprende mejor para explicar más, obteniendo de todo ello la apropiación como transformación en el lector, y si la interpretación de textos literarios agrega la experiencia de la resistencia ante un modo especialmente lingüístico -atractivo- de haber adquirido esa configuración, la interpretación de sí que pareciera interesante recoger de esos procesos es aquella que revela al lector transformado en su momento de búsqueda, de trabajo consigo y con el sentido, antes que de hallazgo. Y aun si se tratase de hallazgos, el de la incomprensibilidad acerca del surgimiento es seguramente el logro más lúcido que pueda conseguir. 